$07.2 ; 09.4$

\title{
Микрооптопара на базе микродискового лазера и фотодетектора с активной областью на основе квантовых ям-точек
}

\author{
() Н.В. Крыжановская ${ }^{1,2}$, Э.И. Моисеев ${ }^{1,2}$, А.М. Надточий ${ }^{1,2}$, А.А. Харченкоㄱ, М.М. Кулагина ${ }^{3}$, \\ С.А. Минтаиров ${ }^{3}$, Н.А. Калюжный ${ }^{3}$, М.В. Максимов ${ }^{2,3}$, А.Е. Жуков ${ }^{1}$ \\ ${ }^{1}$ Национальный исследовательский университет „Высшая школа экономики“, Санкт-Петербург, Россия \\ ${ }^{2}$ Санкт-Петербургский национальный исследовательский Академический университет им. Ж.И. Алфёрова РАН, \\ Санкт-Петербург, Россия \\ ${ }^{3}$ Физико-технический институт им. А.Ф.Иофффе РАН, Санкт-Петербург, Россия \\ E-mail: nataliakryzh@gmail.com
}

Поступило в Редакцию 23 марта 2020 г.

В окончательной редакции 23 марта 2020г.

Принято к публикации 26 марта 2020г.

Показана возможность детектирования излучения микродискового лазера диаметром $23 \mu \mathrm{m}$ с активной областью на основе квантовых ям-точек InGaAs/GaAs с помощью близкорасположенного фотодетектора $(100 \times 4000 \mu \mathrm{m})$ с аналогичной активной областью. При непрерывном режиме работы лазера, токе накачки $20 \mathrm{~mA}$ и расстоянии между гранями микролазера и фотодетектора около $100 \mu \mathrm{m}$ получена величина фототока $\sim 10 \mu \mathrm{A}$, что соответствует чувствительности фотодетектора $\sim 0.9 \mu \mathrm{A} / \mu \mathrm{W}$.

Ключевые слова: полупроводниковый лазер, микродисковый лазер, квантовая яма-точка, микрооптопара.

DOI: 10.21883/PJTF.2020.13.49582.18301

Полупроводниковые резонаторы дисковой геометрии, в которых поддерживаются моды шепчущей галереи (МШГ, whispering gallery modes, WGMs), могут служить основой для создания энергоэффективных и малогабаритных источников когерентного излучения, пригодных для различных приложений [1-3]. Помимо малого объема моды и высокой добротности, присущих МШГ-микрорезонаторам [4], они обладают высокой чувствительностью к изменениям и возмущениям в окружающей резонатор среде [5]. Поле МШГ экспоненциально спадает за боковой поверхностью резонатора на расстоянии 10-100 nm и, таким образом, может взаимодействовать с материалом за пределами резонатора [6]. В связи с этим МШГ-микрорезонаторы являются очень привлекательными для создания сенсоров биомаркеров, ДНК и белков в низких концентрациях, а также для детектирования вирусов и наночастиц с одночастичным разрешением [7-9]. Для этих и других практических приложений желательно использовать оптопару, т.е. объединить полупроводниковый МШГ-микролазер с фотодетектором малого размера. Такие оптопары с открытым оптическим каналом, доступным для внешнего воздействия, могут использоваться в качестве различных типов микродатчиков (биосенсор, детектирование наночастиц), для гальванической развязки, бесконтактного управления и т.д.

Несмотря на то что использование в качестве активной области микродисковых лазеров квантовых точек InAs/InGaAs/GaAs дает такие преимущества, как высокая рабочая температура, улучшенная температурная стабильность характеристик, низкий пороговый ток, слабая чувствительность к безызлучательной рекомбинации, выходная мощность инжекционного микролазе- ра, испускаемая в свободное пространство, довольно мала [10]. Тем не менее в работе [11] было продемонстрировано детектирование излучения микродискового лазера диаметром $100 \mu \mathrm{m}$ с квантовыми точками InAs/InGaAs/GaAs с помощью близкорасположенного детектора, выполненного из той же эпитаксиальной гетероструктуры. Для улучшения вывода излучения из микролазера на его боковой поверхности был сформирован рассеиватель [11]. Недавно мы продемонстрировали, что новая активная область с квантовыми ямами-точками (КЯТ) InGaAs/GaAs имеет преимущества для применения в фотонных устройствах малого размера (порядка $10 \mu \mathrm{m})$, о чем свидетельствует резкое улучшение дифференциальной эффективности и выходной мощности, излучаемой в свободное пространство: получено значение выходной оптической мощности на уровне $18 \mathrm{~mW}$ в микродисковом лазере диаметром $31 \mu \mathrm{m}$ [12].

В настоящей работе исследуется возможность детектирования излучения микродискового лазера с активной областью на основе КЯТ InGaAs/GaAs с помощью близкорасположенного фотодиода, выполненного с использованием такой же эпитаксиальной гетероструктуры. Получено детектирование лазерного излучения микролазера диаметром $23 \mu \mathrm{m}$ с помощью фотодиода, грань которого расположена на расстоянии от 100 до $1400 \mu \mathrm{m}$. Выполнена оценка чувствительности детектора не хуже $0.9 \mu \mathrm{A} / \mu \mathrm{W}$.

Эпитаксиальные структуры выращивались методом металлоорганической газофазной эпитаксии при пониженном давлении с использованием водорода в качестве газа-носителя при температурах $500-700^{\circ} \mathrm{C}$. В качестве источников атомов $\mathrm{Ga}, \mathrm{Al}, \mathrm{In}$ и $\mathrm{Zn}$ были использованы 
металлоорганические соединения триметилгаллий, триметилиндий, триметилалюминий и диэтилцинк. Гидриды арсина $\left(\mathrm{AsH}_{3}\right)$ и силана $\left(\mathrm{SiH}_{4}\right)$ использовались в качестве источников атомов $\mathrm{As}$ и $\mathrm{Si}$ соответственно. Структуры состояли из эмиттерных слоев $\mathrm{Al}_{0.34} \mathrm{Ga}_{0.66} \mathrm{As}$, легированных примесями $p$ - и $n$-типа, и нелегированного волноводного слоя GaAs толщиной $0.8 \mu \mathrm{m}$. Активная область гетероструктур для микролазера и фотодиода содержала пять и десять слоев КЯТ InGaAs соответственно. КЯТ были сформированы осаждением восьми монослоев $\mathrm{In}_{0.4} \mathrm{Ga}_{0.6} \mathrm{As}$ и разделены спейсерами GaAs толщиной $40 \mathrm{~nm}$. Для формирования выраженных неоднородностей толщины и состава в слоях InGaAs были использованы разориентированные подложки GaAs [13]. Микролазеры с диаметром мезы $D=23 \mu \mathrm{m}$ формировались методами фотолитографии и сухого травления (STE ICPe68). Высота мезы составляла около $5.5 \mu \mathrm{m}$ для обеспечения достаточного оптического ограничения мод шепчущей галереи. Вертикальность боковой стенки контролировалась с точностью до $5^{\circ}$. Металлизация $\mathrm{AgMn} / \mathrm{Ni} / \mathrm{Au}$ и $\mathrm{AuGe} / \mathrm{Ni} / \mathrm{Au}$ использовалась для формирования омических контактов с покрывающим слоем $p^{+}$-GaAs и подложкой $n$-GaAs соответственно (вставка к рис. 1). Фотодиодные структуры были изготовлены в форме параллелепипеда, выколотого вдоль основных кристаллографических направлений. В качестве $p$-контакта на поверхности фотодиода создавался полосок шириной $100 \mu \mathrm{m}$ с использованием сплава $\mathrm{AgMn} / \mathrm{Ni} / \mathrm{Au}$ толщиной $0.1-0.15 \mu \mathrm{m}$. Длина полоска составила $4000 \mu \mathrm{m}$. В качестве $n$-контакта использовалась традиционная металлизация сплава $\mathrm{AuGe}$ и $\mathrm{Ni}$, наносимая методом термического испарения на обратную сторону подложки. Светопоглощающие грани фотодиодных структур были сформированы с помощью колки кристаллов без нанесения дополнительных антибликовых покрытий. Исследования спектров излучения микролазеров выполнялись в непрерывном режиме накачки при комнатной температуре с использованием игольчатых зондов в качестве контактов к верхнему дисковому электроду и сплошному электроду со стороны подложки. Выходящее излучение собиралось в плоскости выходного излучения микролазера с помощью микрообъектива Olympus LMPlan IR $\times 10$ и регистрировалось оптическим спектроанализатором (Yokogawa AQ 6370C). Исследования фототока фотодиода с КЯТ были выполнены при освещении поверхности фотодиода излучением с выделенной длиной волны в спектральном диапазоне 800-1200 nm. Использовалось излучение галогеновой лампы, пропущенное через монохроматор МДР6. Также были выполнены исследования отклика фотодиода, возбуждаемого излучением микродискового лазера. В качестве источника тока накачки микролазера во всех случаях использовался источник-измеритель Keithley 2401.

На рис. 1 представлен спектр фототока фотодиода с КЯТ. Полученная зависимость демонстрирует максимальные значения фотоотклика в спектральной обла-

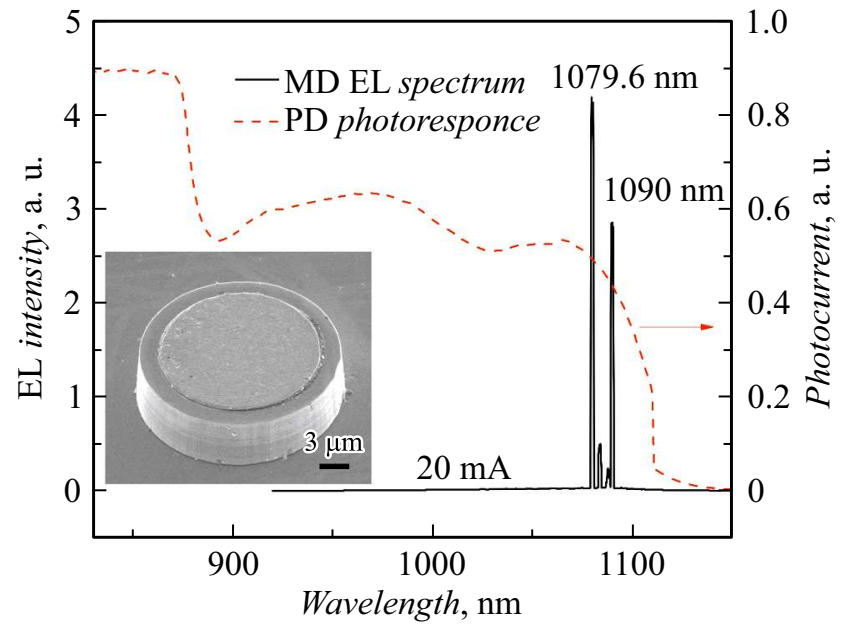

Рис. 1. Спектр электролюминесценции микролазера диаметром $23 \mu \mathrm{m}$ (сплошная линия), полученный при комнатной температуре, и спектральная зависимость фотоотклика фотодиода с КЯТ, возбуждаемого галогеновой лампой (штриховая линия). На вставке - микрофотография микролазера.

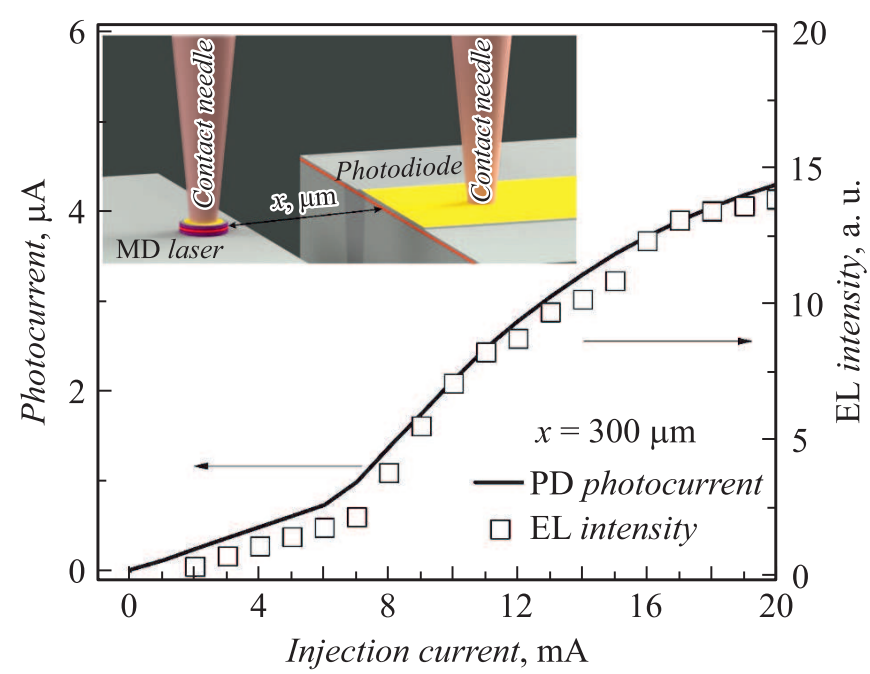

Рис. 2. Зависимости интенсивности электролюминесценции доминирующей линии МШГ-лазера, измеренной спектроанализатором (точки), и фототока фотоприемника оптопары от тока инжекции (сплошная линия). На вставке - схематическое изображение микролазера и фотоприемника, расположенного на расстоянии $x$.

сти, соответствующей поглощению в объемном GaAs до $\sim 880 \mathrm{~nm}$. При дальнейшем увеличении длины волны наблюдается уменьшение величины фототока, вызванное меньшим поглощением света в КЯТ; на спектральной зависимости наблюдаются максимумы, соответствующие возбужденному и основному состояниям в КЯТ ( 980 и $\sim 1070 \mathrm{~nm}$ ). Увеличение длины волны падающего света более $1070 \mathrm{~nm}$ приводит к резкому падению величины фототока, что связано с уменьшением плотности состояний в КЯТ. Спектр генерации микродискового лазера является многомодовым, спектральное положение 


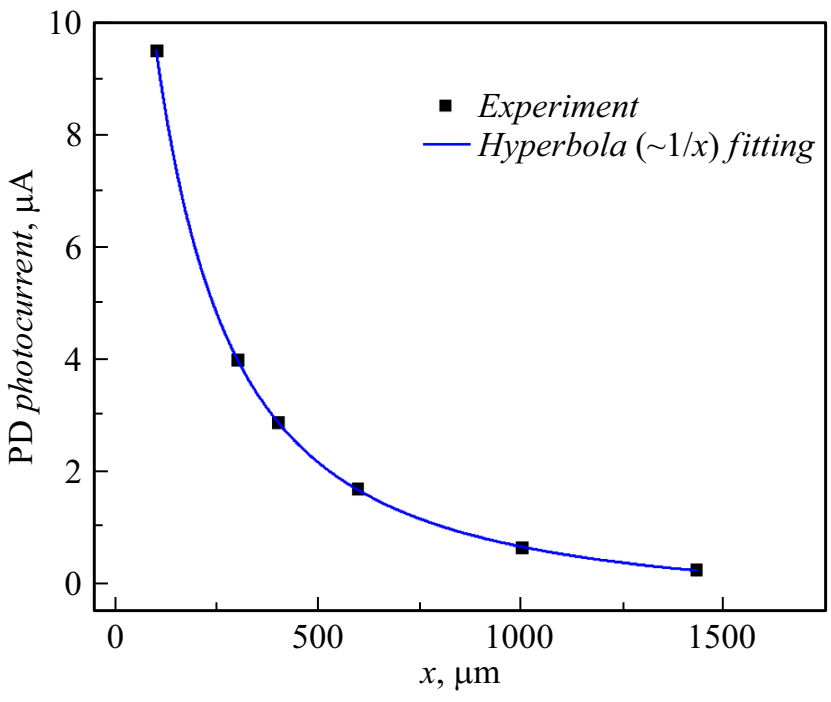

Рис. 3. Зависимость фототока КЯТ фотоприемника от расстояния между лазером и фотоприемником $(x)$. Точки - экспериментальные данные, сплошная линия - аппроксимация функцией вида $f \sim 1 / x$.

доминирующей линии $(1079.6 \mathrm{~nm})$ (рис. 1) находится в области спада фототока. Такой длинноволновый сдвиг линии генерации лазера связан с разогревом микролазера при протекании тока инжекции. Переход от спонтанного излучения к лазерной генерации проявляется в выраженном изломе на зависимости интенсивности доминирующей линии МШГ от тока инжекции (рис. 2) и сопровождается сужением ширины линии. При достижении порога лазерной генерации полуширина доминантной линии падает до $18 \pm 2 \mathrm{pm}$, что является пределом разрешения нашей спектральной системы. Пороговый ток лазерной генерации составил $I_{t h}=7 \mathrm{~mA}$, что соответствует пороговой плотности тока $j_{t h} \sim 0.7 \mathrm{kA} / \mathrm{cm}^{2}$.

Далее микролазер был расположен в непосредственной близости от фасетки фотодиода, обратное смещение к фотоприемнику не прикладывалось, величина темнового тока не превышала $80 \mathrm{nA}$. Зависимость фототока фотоприемника от тока инжекции лазера представлена на рис. 2 (приведены абсолютные значения фототока). При малых токах накачки в области регистрации спонтанного излучения фототок меняется слабо, а затем вблизи порогового тока наблюдается перегиб в соответствии с ходом интенсивности доминирующей линии МШГ-лазера, что подтверждает детектирование именно лазерной линии.

При увеличении расстояния между фасеткой фотодиода и резонатором лазера $(x)$ от 100 до $1400 \mu \mathrm{m}$ величина фототока спадает обратно пропорционально расстоянию $(x)$, что обусловлено расходимостью выходящего лазерного излучения в латеральном и вертикальном направлениях (рис. 3). При расстоянии между элементами микрооптопары $100 \mu \mathrm{m}$ и токе накачки микролазера $20 \mathrm{~mA}$ фототок составляет $9 \mu \mathrm{A}$. Сред- нее значение эффективности преобразования мощности в лазере составляет около 5\% [12]. Электрическая мощность, потребляемая микролазером, составляет $1.9 \mathrm{~V} \cdot 20 \mathrm{~mA}=38 \mathrm{~mW}$, что соответствует выходной оптической мощности $P_{\text {out }} \sim 1.9 \mathrm{~mW}$, излучаемой однородно во всех направлениях в плоскости структуры. При этом расходимость лазерного излучения в вертикальном направлении составляет около $20^{\circ}$. Таким образом, при использованном расстоянии между элементами оптопары лишь $0.75 \%$ мощности лазера $P_{\text {out }}$ (что соответствует $P \sim 14 \mu \mathrm{W})$ достигает поверхности детектора в области волноводного слоя GaAs с поглощающими слоями КЯТ InGaAs. C учетом того, что $30 \%$ излучения отражается от поверхности фотодиода, поглощается около $10 \mu \mathrm{W}$ мощности лазера. Таким образом, можно оценить чувствительность такого детектора как $9 \mu \mathrm{A} / 10 \mu \mathrm{W}$. Некоторое увеличение чувствительности оптопары возможно при сдвиге в более длинноволновую область края поглощения детектора при приложении обратного смещения. Увеличить абсолютное значение фототока позволит дальнейшее уменьшение расстояния между лазером и фотоприемником $(x)$ вплоть до $10 \mu \mathrm{m}$ или формирование элемента вывода излучения из микролазера $[11,13]$.

В результате в работе исследована величина фототока между элементами микрооптопары на базе микродискового лазера диаметром $23 \mu \mathrm{m}$ и фотодетектора с активной областью на основе КЯТ InGaAs. Показана возможность создания компактных приемопередатчиков для систем передачи данных, микродатчиков, бесконтактного управления и прочих приложений.

\section{Финансирование работы}

Работы по созданию микролазера и фотоприемника и исследованию их характеристик выполнены при поддержке Российского научного фонда (соглашение № 1812-00287). Исследования фототока фотодиода осуществлены в рамках Программы фундаментальных исследований НИУ ВШЭ в 2020 г.

\section{Конфликт интересов}

Авторы заявляют, что у них нет конфликта интересов.

\section{Список литературы}

[1] Noh W., Dupré M., Ndao A., Kodigala A., Kanté B. // ACS Photonics. 2019. V. 6. P. 389-394.

[2] Shi B., Zhu S., Li Q., Wan Y., Hu E.L., Lau K.M. // ACS Photonics. 2017. V. 4. P. 204-210.

[3] Kryzhanovskaya N.V., Moiseev E.I., Zubov F.I., Mozharov A.M., Maximov M.V., Kalyuzhnyy N.A., Mintairov S.A., Guseva Yu.A., Kulagina M.M., Blokhin S.A., Berdnikov Yu., Zhukov A.E. // J. Appl. Phys. 2019. V. 126. P. 063107.

[4] Городецкий М.Л. Оптические микрорезонаторы с гигантской добротностью. М.: Физматлит, 2011. 416 с. 
[5] Foreman M.R., Swaim J.D., Vollmer F. // Adv. Opt. Photon. 2015. V. 7. P. $168-240$.

[6] Soria S., Berneschi S., Brenci M., Cosi F., Nunzi Conti G., Pelli S., Righini G.C. // Sensors. 2011. V. 11. P. 785-805.

[7] Arnold S., Khoshsima M., Teraoka I., Holler S., Vollmer F. // Opt. Lett. 2003. V. 28. P. 272-274.

[8] Lin S., Crozie K.B. // ACS Nano. 2013. V. 7. P. 1725-1730.

[9] Dantham V.R., Holler S., Kolchenko V., Wan Z., Arnold S. // Appl. Phys. Lett. 2012. V. 101. P. 043704.

[10] Зубов Ф.И., Крыжсановская Н.В., Моисеев Э.И., Полубавкина Ю.С., Симчук О.И., Кулагина М.М., Задиранов Ю.М., Трошков С.И., Липовский А.А., Максимов М.В., Жуков А.Е. // ФТП. 2016. Т. 50. В. 10. С. 1425-1428.

[11] Wan Y., Zhang Z., Chao R., Norman J., Jung D., Shang C., Li Q., Kennedy M.J., Liang D., Zhang C., Shi J.-W., Gossard A.C., Lau K.M., Bowers J.E. // Opt. Express. 2017. V. 25. P. 27715.

[12] Moiseev E., Kryzhanovskaya N., Maximov M., Zubov F., Nadtochiy A., Kulagina M., Zadiranov Yu., Kalyuzhnyy N., Mintairov S., Zhukov A. // Opt. Lett. 2018. V. 43. P. 45544557.

[13] Mintairov S.A., Kalyuzhnyy N.A., Lantratov V.M., Maximov M.V., Nadtochi A.M., Rouvimov S., Zhukov A.E. // Nanotechnology. 2015. V. 26. P. 385202. 